\title{
Necrose avascular da cabeça femoral em pacientes pediátricos acometidos por disfunção do quadril
}

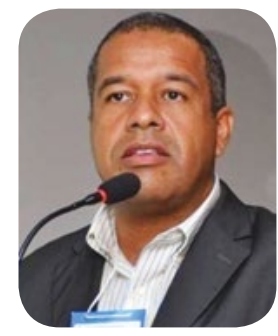

\author{
Marcos Almeida Matos ${ }^{1}$, Marilda Castelar ${ }^{2}$
}

\begin{abstract}
Artigo original: Marcos Almeida Matos, Jandrice Carrasco, Luanne Lisle, Marilda Castelar. Avascular necrosis of the femoral head in sickle cell disease in pediatric patients suffering from hip dysfunction. Rev Salud Pública 2016; 18(6): 986-995.
\end{abstract}

\section{INTRODUÇÃO}

A anemia falciforme é a doença hematológica hereditária mais comum no mundo e a mais prevalente no Brasil. A Bahia apresenta a maior prevalência da doença $(5,48 \%)$, seguida de Alagoas $(4,83 \%)$, Piauí $(4,77 \%)$ e Pará $(4,40 \%)$. A doença falciforme gera grave anemia associada a fenômenos tromboembólicos e vaso-oclusivos. Estima-se que 4 a $12 \%$ destes fenômenos corram na microcirculação óssea, propiciando crises dolorosas (crises falcêmicas), infecções, infartos ósseos e osteonecrose da cabeça femoral (ONCF).

ONCF é uma entidade clínica que resulta da diminuição ou interrupção do fluxo sanguíneo para a cabeça femoral, levando à necrose óssea, perda do trabeculado medular e colapso subcondral, gerando deformidade com destruição articular secundária. É uma condição grave do quadril, associada à dor e, consequentemente, limitação para atividades de lazer e de vida diária.

A OCNF na anemia falciforme tem uma relação direta com a idade, sendo sua prevalência de aproximadamente $3 \%$ em menores de 15 anos, subindo para 8,7 a $12,4 \%$ até 21 anos e progredindo para cifras maiores que $50 \%$ na população acima de 35 anos. A abordagem da osteonecrose na população pediátrica seria, portanto, o ponto de partida para evitar a instalação e progressão da doença articular.

O objetivo do estudo foi verificar a prevalência de ONCF em pacientes com anemia falciforme portadores de disfunção do quadril, na faixa etária infantil, e avaliar a presença de fatores de risco associados à ONCF nestes indivíduos.

\section{MATERIAL E MÉTODOS}

Foi realizado estudo seccional comparativo (descritivo e analítico) em um grupo de pacientes portadores de doença falciforme e disfunção do quadril originários do Centro de Hematologia e Hemoterapia do Estado da Bahia (HEMOBA) e avaliados no ambulatório de Ortopedia Pediátrica do Hospital Santa Izabel, para verificação da presença de necrose avascular da cabeça femoral.

Os participantes do estudo foram divididos em um grupo denominado "Grupo NAV", que reuniu os pacientes com diagnóstico confirmado de NAV; e em outro grupo denominado "Grupo Comparação", que reuniu os não-portadores de NAV.

Este estudo avaliou a condição clínica dos quadris de 92 indivíduos com doença falciforme menores de 21 anos. Do total de pacientes avaliados, 43 apresentaram quadris considerados disfuncionais. Trinta e três indivíduos foram avaliados por anamnese, exame clínico e questionário padronizado para coleta de dados sóciodemográficos. A avaliação radiográfica foi realizada utilizando os critérios de Ficat e Arlet para pacientes com anel epifisário fechado, e de Catterral e Lloyd-Roberts para pacientes com anel epifisário aberto.

\section{RESULTADOS}

Tomando-se como base o número original de 92 sujeitos no início do estudo, 43 indivíduos apresentaram disfunção do quadril, o que representa $46,7 \%$ do total. Dos pacientes que compareceram para reavaliação (33 no total), 13 tiveram o diagnóstico de necrose avascular da cabeça femoral (NAV) confirmado. Isto significa que a prevalência global de ONCF no nosso estudo foi de $39,4 \%$ entre os pacientes com disfunção do quadril. Desta forma, o Grupo NAV foi composto por 13 indivíduos e o Grupo Comparação alocou 20 outros pacientes.

\section{DISCUSSÃO}

Nossos resultados demonstraram que a prevalência de necrose avascular da cabeça femoral em pacientes pediátricos portadores de disfunção clínica do quadril é de $39,4 \%$. Também foi possível evidenciar 
que a osteonecrose esteve associada significativamente com maior altura dos pacientes, maior tempo de diagnóstico, trauma prévio e presença de dor no quadril; menor média do escore de Chanrley, menor taxa de hemoglobina fetal e maior valor de hemoglobina.

É possível que altos níveis de $\mathrm{HbF}$ atuem como proteção, especialmente contra comorbidades que se relacionam com vaso-oclusão e aumento da viscosidade. As células contendo alto teor de HbF (cerca de $20 \%$ ), chamadas células $F$, têm uma sobrevivência mais prolongada que as células chamadas não $\mathrm{F}$, que contêm apenas $\mathrm{HbS}$. Em estudos experimentais também já foi possível revelar que altos níveis de $\mathrm{HbF}$ presente nos eritrócitos são capazes de atrasar o processo de polimerização da hemoglobina, tendo em vista que a mistura $\mathrm{HbF}-\mathrm{HbS}$ produz um efeito antipolimerizador com potencial de inibir até $50 \%$ da polimerização da $\mathrm{HbS}$.

Nosso artigo apresenta pela primeira vez na literatura científica a relevante associação entre disfunção clínica do quadril e osteonecrose da cabeça femoral. A osteonecrose, nestes casos, esteve associada à menor taxa de hemoglobina fetal $(7,2$ versus 11,8$)$, dando suporte à hipótese de que a hemoglobina fetal pode funcionar com fator de proteção contra a necrose avascular.

1- Serviço de Ortopedia do HSI

E-mail para contato:

marcos.almeida@hotmail.com 